Journal of Management and Bussines (JOMB)

Volume 1, Nomor 1, Juni 2019

DOI : https://doi.org/10.31539/jomb.v1i1.598

\title{
PERAN BUDAYA KAIZEN DAN REWARD DALAM MENINGKATKAN KINERJA KARYAWAN
}

\author{
Tiara Suci Bentar ${ }^{1}$, Acep Samsudin ${ }^{2}$, Nor Norisanti ${ }^{3}$ \\ Univesitas Muhammadiyah Sukabumi ${ }^{123}$ \\ tiarasucibentar23@gmail.com
}

\begin{abstract}
ABSTRAK
Tujuan penelitian ini adalah untuk mengetahui dan menganalisis peran budaya kaizen dan reward dalam meningkan kinerja karyawan pada PT. Pos Indonesia (persero) sukabumi. Penelitian ini menggunakan data primer berupa hasil jawaban kuisioner dan data sekunder melalui dokumen-dokumen. Metode analisis data yang digunakan adalah analisis deskriptif dan asosiatif. metode penelitian yang digunakan dalam penelitian ini adalah penelitian penjelasan dengan pendekatan kuantitatif. Jenis Metode penelitian ini menggunakan jenis sampel non probability sampling termasuk kedalam sampel jenuh. Teknik analisis data yang digunakan adalah uji validitas, uji reliabilitas, analisis regresi linear berganda, termasuk uji koefisien determinasi dan koefisien korelasi ganda. Hasil penelitian, uji koefisien determinasi dilihat dari nilai (Adjusted $\mathrm{R}^{2}$ ) sebesar 0,251 dapat diartikan bahwa peran budaya kaizen dan reward dalam meningkatkan kinerja karyawan adalah sebesar $25,1 \%$. Sisanya $74,9 \%$ dipengaruhi oleh faktor-faktor lain diluar penelitian ini. Berdasarkan uji koefisien korelasi ganda dilihat dari nilai R sebesar 0,532, menunjukan bahwa terjadi hubungan yang sedang antara budaya kaizen dan reward dengan kinerja karyawan. Simpulan, budaya kaizen dan reward berpengaruh terhadap kinerja karyawan
\end{abstract}

Kata Kunci : Budaya Kaizen, Reward, Kinerja

\section{ABSTRACT}

The purpose of this study was to find out and analyze the role of kaizen culture and rewards in increasing employee performance at PT. Pos Indonesia (persero) sukabumi. This study uses primary data in the form of questionnaire answers and secondary data through documents. The data analysis method used is descriptive and associative analysis. The research method used in this study is explanatory research with a quantitative approach. This type of research method uses a type of non-probability sampling included in the saturated sample. The data analysis technique used is the validity test, reliability test, multiple linear regression analysis, including the test of the coefficient of determination and multiple correlation coefficients. The results of the test coefficient of determination seen from the value (adjusted R2) of 0.251 can be interpreted that the role of kaizen culture and rewards in improving employee performance amounted to $25.1 \%$. The remaining $74.9 \%$ is influenced by other factors outside of this study. Based on the multiple correlation coefficient test seen from the $R$ value of 0.532, it shows that there is a moderate relationship between kaizen culture and reward with employee performance.

Keywords: Kaizen Culture, Reward, Performance. 


\section{PENDAHULUAN}

Perkembangan sektor jasa di Indonesia saat ini mengalami peningkatan yang cukup pesat. Dalam beberapa tahun ini Berdasarkan Badan pusat statistik (BPS) pada konferensi pers (2017) sektor jasa tumbuh 5,69 persen, lebih tinggi daripada pertumbuhan nasional 5,07 persen dan sektor lainnya manufaktur 4,95 persen dan agrikultur 2,59 persen. Dunia bisnis mengalami kemajuan di setiap tahunnya, hal ini di tandai bahwa banyak nya perusahaan-perusahaan yang berdiri di indonesia, tidak hanya di kota besar saja akan tetapi sudah banyak berdiri di penjuru kota di seluruh Indonesia seperti di kota sukabumi. Semua perusahaan tentunya memiliki tujuan dan sasaran yang sama yaitu keberhasilan dalam menjalankan usahanya, dan mempertahankan perusahaan tersebut agar tidak bangkrut serta memproleh laba yang sebesar-besarnya. Agar semuanya dapat terealisasikan, perusahaan harus mampu menjalankan manajemen yang baik terutama pada manajemen sumber daya manusia harus bisa bekerja secara efektif dan efisien.

Sumber daya manusia sebagai rangkaian strategi, proses dan aktivitas yang di desain untuk menunjang tujuan perusahaan dengan cara mengintegrasikan kebutuhan perusahaan. Manajemen sumber daya manusia dapat didefinisikan pula sebagai suatu pengelolaan dan pendayagunaan sumber daya yang ada pada individu (karyawan) pengelolaan dan pendayagunaan tersebut dikembangkan secara maksimal di dalam dunia kerja untuk mencapai tujuan organisasi dan pengembangan individu karyawan, dalam hal ini karyawan merupakan faktor paling penting yang menjadi penggerak utama dari setiap organisasi atau perusahaan. Oleh sebab itu perusahaan memerlukan sumber daya manusia untuk mengatur karyawan agar dapat bekerja sesuai dengan peraturan yang telah ditetapkan dan dapat menghasilkan pekerjaan dengan baik. manajemen sumber daya manusia adalah pendayagunaan,pengembangan, pengembangan, penilaian, pemberian balas jasa dan pengelolaan individu anggota organisasi atau kelompok pekerja. (Simamora dalam Sutrisno, 2009)

Meningkatkan kinerja karyawan perusahaan memerlukan individu yang berkompetensi dan memiliki kemampuan dalam bekerja karena karyawan yang berkompetensi sangat penting untuk meningkatkatkan perusahaan agar dapat tercapainya target yang sudah di tetapkan. Kinerja karyawan merupakan salah satu aset yang dimiliki perusahaan, perusahaan yang berkembang dan maju maka dilihat dari 
seberapa berkualitas nya kinerja karyawan di sebuah perusahaan tersebut. Jika kinerja karyawan nya sangat baik maka akan sangat menguntungkan bagi perusahaan, dan sebaliknya jika kinerja perusahaan nya tidak baik maka perusahaan tersebut tidak akan berkembang dan maju. kinerja adalah prestasi kerja atau hasil kerja (output) baik kualitas maupun kuantitas yang dicapai Sumber daya manusia dalam melaksanakan tugas kerjanya sesuai dengan tanggungjawab yang diberikan kepadanya. (Mangkunegara, 2016)

Meningkatkan kinerja karyawan, perusahaan harus menerapkan suatu strategi agar karyawan setiap hari nya melakukan perubahan terus-menerus dan menjadi karyawan yang berkualitas. Di negara Jepang ada satu budaya organisasi yang sangat berperan penting pada perusahaan-perusahaan di Jepang yaitu budaya Kaizen. Budaya Kaizen adalah strategi perusahaan untuk menciptakan sumber daya manusia yang berkualitas, budaya Kaizen merupakan budaya perbaikan secara terus menerus untuk meningkatkan mutu dan produktifitas karyawan (Haizer, Jay, Render, 2009). Menurut Imai (2008) menyatakan bahwa budaya Kaizen merupakan budaya yang berasal dari masyarakat Jepang. Kaizen merupakan suatu istilah dari Jepang yang berarti suatu perbaikan yang berkesinambungan. Budaya Kaizen merupakan suatu budaya perbaikan yang melibatkan semua orang, baik manajer maupun para karyawan.

Untuk menunjang budaya Kaizen yang maksimal dan sesuai harapan, di Dalam konsep manajemen, Reward merupakan salah satu alat untuk meningkatkan motivasi kinerja karyawan, metode ini bisa mengasosiasikan perbuatan dan perlakuan seseorang dengan perasaan bahagia, senang, dan biasanya akan membuat mereka melakukan perubahan yang baik secara berulang-ulang. Pentingnya pemberian Reward atau kompensasi sebagai salah satu cara perusahaan agar karyawan mempunyai tangung jawab terhadap perusahaan (Danti, 2014).

Pos Indonesia (persero) sukabumi selalu berusaha meningkatkan kualitas sumber daya manusianya. Untuk itu kualitas karyawan dan segala keperluan yang mendukung kelancaran pekerjaan dan lingkungan kerja harus selalu ditingkatkan. PT. Pos Indonesia (persero) sukabumi yaitu termasuk perusahaan yang menerapkan budaya Kaizen dan Reward dalam meningkatkan kinerja karyawan.

Tema yang di usulkan adalah budaya kaizen dan reward dalam meningkatkan kinerja karyawan pada PT. Pos Indonesia (persero) sukabumi. Tujuan Penelitian ini 
untuk mengetahui dan menganalisis seberapa besar pengaruh budaya kaizen dan reward dalam meningkatkan kinerja karyawan.

\section{KAJIAN TEORI}

\section{Budaya Kaizen}

Budaya Kaizen yaitu suatu pemikiran yang berdasarkan pada keyakinan bahwa orang yang melakukan pekerjaan tertentu akan memperoleh lebih banyak hal dari pada orang yang lain, termasuk atasan mereka, bagaimana pekerjaan itu dapat ditingkatkan, dan bahwa mereka harus dapat bertanggung jawab untuk membuat suatu perbaikan, Setiap management yang terdapat dalam perusahaan seharusya dapat melakukan suatu perbaikan terus menerus dalam operasinya dengan membuat perubahan kecil pada setiap hari. (Khan 2011).

Budaya Kaizen merupakan budaya yang berasal dari masyarakat Jepang. Kaizen merupakan suatu istilah dari Jepang yang berarti suatu perbaikan yang berkesinambungan. Budaya Kaizen merupakan suatu budaya perbaikan yang melibatkan semua orang, baik manajer maupun para karyawan. (Imai, 2008). Dimensi menurut Imai (2008) terdiri dari: 1) pelatihan dan pendidikan karyawan, yaitu perusahaan memberikan pelatihan dan pendidikan bagi karyawan serta membangun pola pikir karyawan untuk meningkatkan kualitas kerjanya, 2) hubungan kerja, yaitu menciptakan hubungan yang hangat antara atasan dan bawahannya, serta hubungan antar karyawan dan karyawan adanya rasa saling percaya, kekeluargaan dan lain sebagainya, 3) kedisiplinan kerja perusahaan harus mendorong karyawan untuk selalu menerapkan kedisiplinan diri ditempat kerja sesuai dengan standar yang telah ditetapkan oleh perusahaan, 4) tempat kerja, tempat kerja, yaitu sejauhmana perusahaan menciptakan suasana dimana karyawan akan merasa bahwa lingkungan kerja menjadi tempat yang nyaman dan kondusif dan akan mendorong produktifitas dan kreatifitas karyawan, serta para karyawan akan merasa memiliki komitmen kepada perusahaan.

\section{Reward}

Reward tidak hanya mencakup unsur kuantitatif seperti gaji, upah dan lain lain, tetapi juga unsur lainnya yang berwujud bukan uang, seperti kesempatan untuk melaksanakan tanggung jawab yang lebih besar, peluang karir, kesempatan untuk 
belajar dan berkembang, kualitas kehidupan yang layak dalam organisasi dan lain-lain. (Thompson dalam Ihedinmah, Egbunike, 2015).

1. Insentif. Insentif merupakan pemberian uang di luar gaji dan yang memberikan yaitu pemimpin perusahaan sebagai bentuk pengakuan terhadap prestasi kerja dan kontribusi pegawai kepada perusahaan. Pada umumnya pemberian insentif senantiasa dihubungkan dengan balas jasa atas prestasi ekstra karyawan yang melebihi suatu standar yang telah ditetapkan serta telah disetujui bersama. Insentif yaitu memberikan penghargaan dalam bentuk pendapatan ekstra untuk usaha ekstra yang dihasilkan.

2. Bonus, pemberian bonus dapat diberikan berdasarkan penghematan waktu. Dengan pembayaran bonus dapat bertindak sebagai insentif bagi para pekerja agar termotivasi untuk meningkatkann kinerjanya. Bonus tahunan biasanya diberikan apabila perusahaan mendapat laba atau keuntungan atau memiliki nilai positif di akhir tahun.

3. Penghargaan secara formal dari pimpinan. Tujuan dari penghargaan formal ini yaitu untuk memberitahukan kepada semua karyawan bahwa salah satu karyawan telah berprestasi dan pantas untuk diberi penghargaan. Penghargaan ini dapat berupa gelar, medali atau sertifikat yang diberikan pada karyawan yang berprestasi. Pada umumnya waktu pemberian penghargaan ini adalah ketika perusahaan tersebut melakukan kegiatan formal.

4. Pujian. Pujian yaitu bentuk reinforcement yang positif dan baik. Pujian yang diucapkan pada waktu yang tepat dapat dijadikan sebagai alat motivasi bagi karyawan.

5. Promosi jabatan. Promosi yaitu jika seorang karyawan dipindahkan dari satu pekerjaan ke pekerjaan lain yang tanggung jawabnya lebih besar dari pada tanggung jawab yang telah dibebankan sebelumnya. Pada dasarnya setiap karyawan menginginkan promosi karena dipandang sebagai penghargaan atas keberhasilan karyawan dalam menunjukkan prestasi kerja yang tinggi, sekaligus untuk pengakuan atas kemampuan dan potensi yang bersangkutan untuk menduduki posisi yang lebih tinggi dalam organisasi. 


\section{Kinerja Karyawan}

Kinerja adalah prestasi kerja atau hasil kerja (output) baik kualitas maupun kuantitas yang dicapai SDM dalam melaksanakan tugas kerjanya sesuai dengan tanggungjawab yang diberikan kepadanya. (Mangkunegara, 2016). Kinerja Karyawan pada umumnya dikaitkan dengan pencapaian hasil standar kerja yang telah ditetapkan. Didalam penelitian ini pengukuran Kinerja Karyawan diarahkan pada enam aspek yang merupakan bidang prestasi kunci bagi organisasi yang bersangkutan. Adapun enam unsur tersebut menurut Sutrisno (2009) adalah; 1) hasil kerja, tingkat kualitas dan kuantitas kerja yang dihasilkan dan sejauh mana pengawasan dilakukan, 2) pengetahuan pekerjaan, tingkat pengetahuan yang terkait dengan tugas pekerjaan yang akan berpengaruh langsung terhadap kuantitas dan kualitas kerja, 3) inisiatif, tingkat inisiatif selama melaksanakan tugas pekerjaan khususnya dalam hal penanganan pada masalah-masalah yang timbul, 4) kecekatan mental, yaitu Tingkat kemampuan dan kecepatan dalam menerima instruksi kerja dan menyesuaikan dengan cara kerja serta situasi kerja yang ada, 5) sikap, yaitu Tingkat semangat kerja serta sikap positif dalam melaksanakan tugas pekerjaan 6) Disiplin Waktu dan Absensi aitu Tingkat ketepatan waktu dan tingkat kehadiran, dan karyawan mengikuti aturan SOP

\section{METODE PENELITIAN}

Penelitian ini dilaksanakan di PT. Pos Indonesia (persero) Kota Sukabumi. Menggunakan pendekatan manajemen sumber daya manusia, yang khususnya membahas tentang budaya kaizen,reward dan kinerja karyawan. Dalam penelitian ini terdapat tiga variabel yang dijadikan kawasan penelitian yaitu budaya kaizen (Variabel $\mathrm{X} 1$ ), reward (Variabel X2), dan kinerja karyawan (Variabel Y). dalam penelitian ini yang dijadikan variabel terikat (dependent variable) yaitu kinerja karyawan, dan yang dijadikan variabel bebas (independent variable) yaitu budaya kaizen dan reward.

Penelitian yang dijadikan variabel bebas (independent variable) adalah budaya kaizen dan Reward. Budaya Kaizen terdiri dari empat dimensi, yaitu : pelatihan dan pendidikan, hubungan kerja, kedisiplinan kerja, dan tempat kerja. Sedangkan Reward terdiri dari lima dimensi, yaitu : insentif, bonus, penghargaan secara formal, pujian, dan promosi jabatan. Dan yang menjadi variabel terikat (dependent variable) adalah kinerja 
karyawan yang meliputi enam dimensi, yaitu : hasil kerja, pengetahuan pekerjaan, inisiatif, kecekatan mental, sikap, disiplin waktu dan absensi.

Populasi dalam penelitian ini adalah karyawan PT. Pos Indonesia (persero) Kota Sukabumi. Metode yang digunakan adalah menggunakan teknik probability sampling dengan metode sampling jenuh dan dengan melakukan penyebaran kuesioner sebanyak 47 kepada karyawan. Teknik analisis yang digunakan adalah uji validitas, uji reliabilitas, teknik analisis koefisien korelasi ganda, koefisien determinasi, regresi linear berganda dan pengujian hipotesis menggunakan uji secara simultan (uji F).

\section{HASIL PENELITIAN}

\section{Hasil Analisis Regresi Linear Berganda}

Regresi linear berganda digunakan untuk mengetahui seberapa besar pengaruh faktor yang digunakan dalam model penelitian budaya kizen dan reward terhadapkinerja karyawan. Hasil regresi linear berganda dapat dilihat pada tabel 1 sebagai berikut:

Tabel 1

Hasil Analisis Regresi Linear Berganda

\begin{tabular}{|c|c|c|c|c|c|c|}
\hline \multicolumn{7}{|c|}{ Coefficients $^{\mathrm{a}}$} \\
\hline \multirow{2}{*}{\multicolumn{2}{|c|}{ Model }} & \multicolumn{2}{|c|}{ Unstandardized Coefficients } & \multirow{2}{*}{$\begin{array}{c}\begin{array}{c}\text { Standardized } \\
\text { Coefficients }\end{array} \\
\text { Beta } \\
\end{array}$} & \multirow[b]{2}{*}{$\mathrm{t}$} & \multirow[b]{2}{*}{ Sig. } \\
\hline & & $\mathrm{B}$ & Std. Error & & & \\
\hline \multirow[t]{3}{*}{1} & (Constant) & 17.385 & 4.072 & & 4.270 & .000 \\
\hline & budaya kaizen & -.185 & .132 & -.177 & -1.402 & .168 \\
\hline & reward & .638 & .139 & .576 & 4.571 & .000 \\
\hline
\end{tabular}

a. Dependent Variable: kinerja karyawan

Tabel 2 di atas menjelaskan Dari output uji regresi linear berganda diatas, maka dapat diperoleh persamaan bagaimana dijelaskan berikut ini :

$$
Y=17.385+0,185 X_{1}+0,638 X_{2}
$$

\section{Hasil Koefisien Determinasi}

Tabel 2

Hasil Koefisien Determinasi

\begin{tabular}{|c|c|c|c|c|}
\hline \multicolumn{5}{|c|}{ Model Summary } \\
\hline Model & $\mathrm{R}$ & R Square & $\begin{array}{l}\text { Adjusted R } \\
\text { Square }\end{array}$ & $\begin{array}{c}\text { Std. Error of the } \\
\text { Estimate }\end{array}$ \\
\hline 1 & $.570^{\mathrm{a}}$ & .325 & .295 & 1.806 \\
\hline
\end{tabular}

Sumber: data primer (kuisioner) 2019 
Hasil tabel 2 diatas model summary besarnya adjusted $\mathrm{R}^{2}$ yaitu 0,295 ; hal ini berarti 29,5\% variasi kinerja karyawan dapat dijelaskan oleh variasi dari dua variabel independen Budaya kaizen dan Reward sedangkan sisanya 70.5\% (100\%$29,5 \%=70,5 \%$ ) dari faktor yang tidak diteliti.

\section{Hasil Koefisien Korelasi Ganda}

Tabel 3

Hasil Koefisien Korelasi Ganda

Model Summary

\begin{tabular}{|c|c|c|c|c|}
\hline Model & $\mathrm{R}$ & R Square & $\begin{array}{c}\text { Adjusted R } \\
\text { Square }\end{array}$ & $\begin{array}{c}\text { Std. Error of the } \\
\text { Estimate }\end{array}$ \\
\hline 1 & $.570^{\mathrm{a}}$ & .325 & .295 & 1.806 \\
\hline
\end{tabular}

a. Predictors: (Constant), reward, budaya kaizen

Sumber: data primer (kuisioner) 2019

Berdasarkan tabel 3 di atas dipeoleh angka $\mathrm{R}$ sebesar 0,570 berada pada katagori 0,40-0,599. Hal ini menunjukan bahwa terjadi hubungan yang sedang antara budaya kaizen dan Reward dengan kinerja karyawan.

\section{Hasil Uji F}

Tabel 4

Hasil Uji F

\begin{tabular}{llr|r|r|r|r}
\hline \multicolumn{7}{c}{ ANOVA $^{\text {a }}$} \\
\hline Model & & Sum of Squares & df & Mean Square & F & \multicolumn{1}{c}{ Sig. } \\
\hline \multirow{2}{*}{1} & Regression & 69.231 & 2 & 34.615 & 10.608 & $.000^{\text {b }}$ \\
\cline { 2 - 8 } & Residual & 143.578 & 44 & 3.263 & & \\
\cline { 2 - 7 } & Total & 212.809 & 46 & & & \\
\hline
\end{tabular}

a. Dependent Variable: kinerja karyawan

b. Predictors: (Constant), reward, budaya kaizen

Sumber : data primer (kuisioner), 2019

Tabel 4 menjelaskan Uji $\mathrm{F}$ variabel $\mathrm{X}_{1}$ (budaya kaizen) $\mathrm{X}_{2}$ (reaward) dan $\mathrm{Y}$ (Kinerja karyawan) adalah sebesar 10.608. dapat di peroleh dari nilai sig. $0,000<0,05$; nilai $F_{\text {hitung }} 10.608>F_{\text {tabel }}$ 3.21. Artinya bahwa budaya kaizen dan reaward secara simultan berpengaruh terhadap kinerja karyawan . 


\section{PEMBAHASAN}

\section{Pengaruh Budaya Kaizen (X1) terhadap Kinerja Karyawan (Y)}

Adapun hubungan antar (X1) terhadap (Y) yaitu. Menurut Imai (2008) menyatakan bahwa "budaya Kaizen sangatlah penting karena merupakan pondasi dalam membuat suatu proses menjadi sependek mungkin, mengurangi biaya produksi, output yang berkualitas dan mengurangi timbulnya keborosan". Hal tersebut akan membantu karyawan dalam bekerja sehingga karyawan mampu menghasilkan kinerja yang berkualitas dan sesuai dengan harapan perusahaan. Sedangkan penelitian Hakim et. all (2016) ada pengaruh signifikan antara variabel penerapan budaya Kaizen terhadap motivasi dan kinerja karyawan. Dengan demikian apabila budaya Kaizen diterapkan di sebuah perusahaan maka kinerja karyawan juga akan meningkat. karena setiap karyawan akan meningkakan kedisiplinan bekerja, mematuhi semua perarturan yang ada, dan akan berusaha secara terus menerus menunjukan hasil kerja yang baik, karyawan akan bertanggung jawab untuk memperbaiki setiap kesalahan kerja, serta menyempurnakan proses kerja dalam rangka mencapai tujuan perusahaan, dari penjelasan tersebut maka dapat disimpulkan bahwa budaya Kaizen sangat berpengaruh terhadap kinerja karyawan dalam perusahaan.

\section{Pengaruh Reward (X2) terhadap Kinerja Karyawan (Y)}

Adapun hubungan (X2) terhadap (Y) yaitu: Menurut Febrianti (dalam Astuti, 2018) menyatakan bahwa penghargaan (reward) berpengaruh positif dan signifikan terhadap kinerja karyawan. Sedangkan Triton (dalam Nugroho, 2015) menyatakan bahwa reward adalah suatu upaya yang dilakukan oleh perusahaan untuk meningkatkan prestasi kerja, motivasi, dan kepuasan kerja para karyawan. Dengan demikian apabila Reward di terapkan dalam sebuah perusahaan maka itu sangat menguntungkan bagi karyawan, karena reward sebuah bentuk apresiasi kepada suatu prestasi yang diberikan dalam bentuk material dan ucapan, dan sangat memotivasi karyawan untuk menjadi lebih baik lagi.

\section{Hubungan Budaya Kaizen (X1) dan Reward (X2) terhadap Kinerja Karyawan (Y).}

Menurut Pamungkas dan Franksiska (2018) dalam penelitian sebelumnya menyatakan bahwa variabel budaya Kaizen dan Reward dapat meningkatkan kinerja 
karyawan, budaya Kaizen dan Reward memiliki pengaruh positif terhadap kinerja karyawan, Jika budaya Kaizen dan Reward dilakukan dengan maksimal atau dengan teratur maka akan berdampak pada kinerja karyawan yang semakin meningkat dan berkualitas", Jadi dapat disimpulkan bahwa budaya kaizen dan Reward dapat memperkuat kinerja karyawan.

Berdasarkan teori-teori yang dikemukakan diatas, penulis dapat menyimpulkan bahwa adanya keterkaitan antar variabel. Dalam hal ini, jelaslah bahwa memang terdapat keterkaitan diantara masing - masing variabel dan saling mempengaruhi. Karna dengan adanya budaya Kaizen dan Reward yang tinggi di dalam perusahaan, karyawan akan merasakan bekerja dengan teratur, disiplin dalam bekerja dan berusaha secara terus menerus melakukan perubahan yang baik di setiap harinya, dan akan terjadi peningkatan pada kinerjanya. akibat positif dari budaya Kaizen dan Reward dan biasanya akan menimbulkan kinerja karyawan yang sangat berkualitas.

\section{Uji Regresi Linear secara Bersama-sama}

Berdasarkan pada hasil hitungan penelitian analisis regresi berganda uji $\mathrm{F}$ dengan tingkat signifikan sebesar 0,5 (5\%) menunjukan bahwa variabel budaya kaizen $\left(\mathrm{X}_{1}\right)$ dan reward $\left(\mathrm{X}_{2}\right)$ berpengaruh secara bersama-sama terhadap kinerja karyawan $(\mathrm{Y})$. Hal ini di tunjukan dengan hasil nilai sig. 0,005 < 0,5; nilai $\mathrm{F}_{\text {hitung }} 10.608<\mathrm{F}_{\text {tabel }} 3.21$. Nilai Koefisien Determinasi $\left(\mathrm{R}^{2}\right)$ diperoleh hasil dari variabel Budaya kaizen $\left(\mathrm{X}_{1}\right)$ dan reward $\left(\mathrm{X}_{2}\right)$ mempengaruhi sebesar 29,5\% (0,295) terhadap kinerja karyawan (Y), sisanya $70,5 \%$ dipengaruhi oleh faktor-faktor lain diluar penelitian ini. Hal ini dikarenakan penting nya budaya kaizen dan reward berperan penting dalam meningkatkan kinerja karyawan. Dengan demikian dapat diketahui bahwa budaya kaizen $\left(\mathrm{X}_{1}\right)$ dan reward $\left(\mathrm{X}_{2}\right)$ merupakan faktor yang membentuk kinerja karyawan $(\mathrm{Y})$ Pada PT. Pos Indonesia (persero) Sukabumi secara simultan.

\section{SIMPULAN}

Penelitian ini bertujuan untuk menganalisis pengaruh budaya kaizen dan reward terhadap kinerja karyawan dan dilakukannya budaya kaizen ini harapann dapat memajukan perusahaan secara berangsur dalam memberikan hasil untuk jangka panjang. Berdasarkan dari hasil analisis yang telah dilakukan, maka dapat disimpulkan bahwa dari hipotesis menunjukkan budaya kaizen dan reward 
berpengaruh terhadap kinerja karyawan. Dalam artian semakin tinggi tingkat budaya kaizen maka kinerja dari karyawan akan semakin besar atau tinggi, dan semakin banyak reward yang diberikan perusahaan untuk karyawan maka semakin baik bagi karyawan untuk melakukan tugasnya. Hasil analisis dalam penelitian ini menunjukkan bahwa budaya kaizen dan reward sangat bepengaruh terhadap kinerja karyawan.

\section{DAFTAR PUSTAKA}

Astuti, S,W, (2018), Pengaruh Reward Dan Punishment Terhadap Kinerja Karyawan, Jurnal Organisasi dan Manajemen. 5 (1): 56-66

Erik, Pamungkas, (2018), Analisis Pengaruh Budaya Kaizen Terhadap Kinerja Karyawan dengan Reward sebagai Variabel Moderasi dalam Rangka Penguatan Daya Saing Bisnis. Universitas Kristen Satya Wacana, 20 (1): 34-44

Fajarrini, P.Hakim Danti, (2014), Pengaruh Kompensasi terhadap Semangat Kerja Karyawan (Studi Pada Karyawan CV. Sejahtera, Pakisaji, Malang), Jurnal Administrasi Bisnis, 9 (2): 89-99

Haizer Jay Dan Barry Render, (2009), Manajemen Oprasi Buku 1 Edisi 9, Jakarta, Salemba 4.

Imai, Masaki, (2008), The Kaizen Power, Think, Yogyakarta.

Khan, Imran Ahmad (2011), Kaizen: The Japanese Strategy For Continuous Research, 1 (3): $177-184$

Mangkunegara, A,P, (2016), Manajemen Sumber Daya Manusia, Bandung, PT. Remaja Rosdakarya.

Mohammad Ariful Hakim, (2016), Pengaruh Budaya Kaizen Terhadap Motivasi Dan Kinerja Karyawan (Studi Pada Karyawan PT. Semen Indonesia Tbk). Universitas Brawijaya, 35 (1): 56-66

Nnaji-ihedinmah, Egbunike, Francis, (2015), Effect of rewards on employee performance in organization: a study of selected commercial banks in awka metropolis.

Nugroho A.D (2015). Pengaruh Reward Dan Punishment Terhadap Kinerja Karyawan PT Business Training And Empowering Management Surabaya. Jurnal Maksipreneur, 4 (2): 90-100

Sutrisno, Edy, (2009), Manajemen Sumber Daya Manusia, Jakarta: Kencana 